\title{
Awareness, potential factors, and post-amputation care of stump flexion contractures among transtibial amputees
}

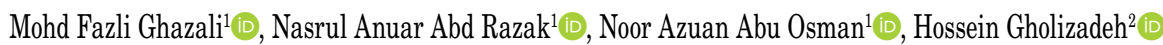 \\ ${ }^{1}$ Department of Biomedical Engineering, University of Malaya, Kuala Lumpur, Malaysia \\ ${ }^{2}$ The Ottawa Hospital Rehabilitation Centre, Ottawa, Canada \\ Received: May 08, 2017 Accepted: November 02, 2017 Published online: July 12, 2018
}

\begin{abstract}
Objectives: This study aims to assess the level of awareness of transtibial amputee patients on stump contractures and their compliance with efforts implemented to prevent the condition.

Patients and methods: This study included 50 unilateral transtibial amputees ( 26 males, 24 females; mean age $55.4 \pm 14.7$ years; range, 18 to 78 years) who met the respondent criteria of the study. The respondents were randomly selected and were issued with a questionnaire.

Results: The majority of the transtibial amputees were aware of stump contracture complications. It was found that they also preferred methods of prevention which required less effort, was cost-effective, and were also practical.

Conclusion: More focus should be placed on contracture prevention methods which were most complied with by the patients. This is because the effectiveness of a prevention method is highly influenced by patients' compliance with the method. Patients with a higher risk of developing stump contractures should be also given more attention in post-amputation care.
\end{abstract}

Keywords: Awareness; knee flexion contracture; post-amputation care; stump contracture; transtibial amputee.

Knee contractures or flexion contractures are one of the most common problems faced among transibial amputees. It is known as a condition where a patient cannot fully straighten the knee. ${ }^{[1,2]}$ The main cause of this phenomenon is the failure of soft tissue at the stump, also known as flexor muscles, to lengthen in tandem with the bone. It occurs when the leg muscles shorten and tighten due to the long periods in a bending position or inactivity due to the illness or lack of exercise. ${ }^{[3,4]}$

The condition has significant impacts on a patient. More specifically, for amputees who have decided to proceed with prosthesis, the presence of a flexion contracture may prevent him/her from achieving successful prosthesis usage. The reason for this is that the contracture disrupts the prosthesis alignment, which could lead to a number of complexities during walking, such as gait deviations. ${ }^{[5,6]}$
According to the literature in this field, stretching is a common method to overcome the problem of contractures. Stretching can be done in three different ways, namely active stretching, manual stretching, and position administration. ${ }^{[1]}$ Nevertheless, according to Finger and Willis, ${ }^{[3]}$ stretching is a secondary method which can prevent contractures; the primary prevention method is active exercise which can be done in conjunction with stretching. In general, the best results for contracture improvement can be achieved through a combination of both stretching and active exercise. It has been found that lying and sitting postures have also influenced the presence of contractures. ${ }^{[5]}$ Thus, in addition to assisting amputees during therapy sessions, consultation from doctors and therapists regarding proper stump positions was also necessary. They also responsible to increase awareness of stump contracture complications among amputees. ${ }^{[7]}$ It's important to note that, amputees'

Corresponding author: Nasrul Anuar Abd Razak, PhD. Department of Biomedical Engineering, Faculty of Engineering, University of Malaya, 50603 Kuala Lumpur, Malaysia. e-mail: nasrul.anuar@um.edu.my 
awareness on stump contracture complications may depend on the hospital environment and facilities where the amputees had the amputation.

Despite all the necessary information shared with and therapy provided to the amputees, it has been found that what has been taught was not being practiced by some of them. This relates to a compliance problem with contracture prevention methods. Indeed, it has been identified that a patient's compliance with the prevention methods is the most important factor in achieving effectiveness in contracture prevention efforts. ${ }^{[8]}$

A majority of amputees in Malaysia are diabetic and elderly patients. Thus, it is expected that diabetic and elderly patients are the most common patients who develop stump contractures, compared to younger amputees. This is because musculoskeletal disorders are normally associated with diabetic complications and an older age's factor. The disorders would lead to a reduction in functional abilities, physical inactivity, and a lower quality of life. ${ }^{[9]}$ Low compliance with contracture prevention methods is also seen among elderly patients. The aim of this study was to identify the level of awareness of transtibial amputees about stump contracture complications and their compliance with prevention efforts.

\section{PATIENTS AND METHODS}

This study included 50 unilateral transtibial amputees (26 males, 24 females; mean age $55.4 \pm 14.7$ years; range, 18 to 78 years). The respondents were randomly chosen from three different companies which served as prosthetic and orthotic suppliers for the state and private hospitals. The companies commonly dealt with orthopedic and rehabilitation departments. The study required the respondents to meet certain criteria to be considered as respondents for the study. Patients which met the required criteria were randomly selected from the companies' records and were called for an appointment at the companies premises. Respondents who were unable to attend the appointment at the companies premises were given the option for the study to be carried out at their houses. The study was conducted under the supervision of the Certified Prosthetics and Orthotics (CPO) of the International Society of Prosthetics and Orthotics (ISPO) Category 1.

The 50 respondents were randomly selected from all ages and both sexes and regardless of left or right amputation side. The selection was selected only after the participants met the following criteria:
1. Unilateral transtibial amputee.

2. Were able to communicate efficiently.

The research protocol for this study was approved by the Medical Research Ethics Committee (MREC), Ministry of Health Malaysia. The Approval ID was: NMRR-16-2106-32880. The MREC understood that the data collection method for this study would only involve a physical evaluation.

Data were collected using a set of questionnaires which were filled in by the respondents. The types of information included in the questionnaire were: demographic data (age and sex), physical data (body weight and height), clinical data (cause of a mputation, degree of knee contracture following treatment after amputation), and respondents personal opinions (most preferred stump contracture prevention mechanisms and stump position during resting). The degree of stump contractures and length of the stumps were measured by the researchers. The stump was considered to have a contracture, when it was unable to fully extend. The degree of contracture was measured as the remaining angle for the stump to achieve a full extension. A contracture angle equal to or more than $10^{\circ}$ was considered to be a significant contracture. The set of questions used in the study questionnaire is presented in Appendix I.

\section{Statistical analysis}

Statistical analysis was performed using the Minitab Express version 1.5.0 (Minitab Inc., PA, USA). The responses were divided into two groups. Each group was independent of each other, which indicated that the two groups/variables were made of unrelated, different, and unpaired individuals. The chi-square $\left(\chi^{2}\right)$ test was performed to determine whether there was a significant association between the two variables. A $p$ value of less than 0.05 was considered statistically significant.

\section{RESULTS}

Table 1 demonstrates that the participants were divided based on the factors of amputation including the presence of stump contractures. There was a significant difference between the contractures occurring among respondents who were amputated due to diabetic complications as opposed to a combination of other causes $(\mathrm{p}=0.001)$.

Figure 1 illustrates a chart of the total respondents with and without stump contractures based on the age 
Table 1. Demographic data of the subjects

\begin{tabular}{|c|c|c|c|c|c|c|}
\hline Subject & Age (years) & Sex & Amputation Side & Cause of amputation & Length of stump (cm) & Degree of contracture $\left({ }^{0}\right)$ \\
\hline 1 & 40 & Male & Left & Diabetes & 13.3 & 4 \\
\hline 2 & 24 & Male & Left & Nervous system & 18.8 & NA \\
\hline 3 & 18 & Male & Right & Congenital & 12.6 & NA \\
\hline 4 & 55 & Female & Left & Diabetes & 14.4 & 7 \\
\hline 5 & 65 & Male & Right & Diabetes & 9.7 & 7 \\
\hline 6 & 67 & Male & Right & Traumatic injury & 12.9 & NA \\
\hline 7 & 68 & Male & Left & Diabetes & 14.7 & 5 \\
\hline 8 & 55 & Female & Left & Diabetes & 16.1 & 7 \\
\hline 9 & 47 & Female & Right & Traumatic injury & 17.0 & 4 \\
\hline 10 & 44 & Male & Right & Diabetes & 11.9 & NA \\
\hline 11 & 72 & Male & Right & Diabetes & 16.3 & 9 \\
\hline 12 & 63 & Female & Left & Diabetes & 13.4 & 5 \\
\hline 13 & 57 & Male & Right & Diabetes & 14.5 & NA \\
\hline 14 & 32 & Male & Right & Bone cancer & 16.9 & NA \\
\hline 15 & 47 & Male & Left & Diabetes & 13.1 & 16 \\
\hline 16 & 54 & Male & Right & Diabetes & 16.7 & 9 \\
\hline 17 & 59 & Male & Left & Bone cancer & 17.7 & NA \\
\hline 18 & 68 & Male & Left & Diabetes & 15.0 & 7 \\
\hline 19 & 78 & Female & Left & Diabetes & 18.1 & 7 \\
\hline 20 & 69 & Male & Right & Diabetes & 12.8 & 4 \\
\hline 21 & 56 & Female & Left & Diabetes & 10.1 & 8 \\
\hline 22 & 58 & Female & Left & Diabetes & 14.8 & NA \\
\hline 23 & 48 & Male & Right & Bone cancer & 11.2 & NA \\
\hline 24 & 28 & Male & Right & Diabetes & 9.9 & 9 \\
\hline 25 & 58 & Male & Right & Diabetes & 12.2 & 5 \\
\hline 26 & 67 & Male & Left & Diabetes & 10.1 & 14 \\
\hline 27 & 62 & Male & Right & Diabetes & 10.9 & $\mathrm{NA}$ \\
\hline 28 & 33 & Female & Left & Traumatic injury & 18.9 & NA \\
\hline 29 & 64 & Female & Right & Diabetes & 12.0 & 6 \\
\hline 30 & 56 & Female & Right & Diabetes & 17.7 & NA \\
\hline 31 & 25 & Male & Left & Traumatic injury & 15.9 & NA \\
\hline 32 & 60 & Female & Left & Diabetes & 17.3 & 8 \\
\hline 33 & 78 & Male & Left & Diabetes & 14.4 & 17 \\
\hline 34 & 67 & Male & Right & Diabetes & 16.8 & NA \\
\hline 35 & 63 & Male & Right & Diabetes & 15.1 & 8 \\
\hline 36 & 48 & Male & Left & Diabetes & 11.2 & 15 \\
\hline 37 & 64 & Female & Right & Diabetes & 16.0 & 7 \\
\hline 38 & 52 & Male & Right & Diabetes & 9.9 & 13 \\
\hline 39 & 64 & Male & Right & Diabetes & 13.8 & NA \\
\hline 40 & 43 & Female & Left & Infection & 11.7 & 5 \\
\hline 41 & 61 & Female & Left & Diabetes & 12.4 & 18 \\
\hline 42 & 76 & Male & Left & Diabetes & 14.4 & 11 \\
\hline 43 & 38 & Male & Right & Traumatic injury & 16.3 & NA \\
\hline 44 & 56 & Male & Left & Infection & 18.1 & NA \\
\hline 45 & 59 & Male & Left & Diabetes & 10.4 & NA \\
\hline 46 & 65 & Male & Right & Diabetes & 13.6 & 6 \\
\hline 47 & 61 & Male & Right & Diabetes & 9.8 & 8 \\
\hline 48 & 69 & Female & Left & Diabetes & 8.8 & 6 \\
\hline 49 & 54 & Male & Right & Diabetes & 15.9 & 6 \\
\hline 50 & 55 & Female & Left & Diabetes & 10.7 & 8 \\
\hline
\end{tabular}

NA: Not available. 


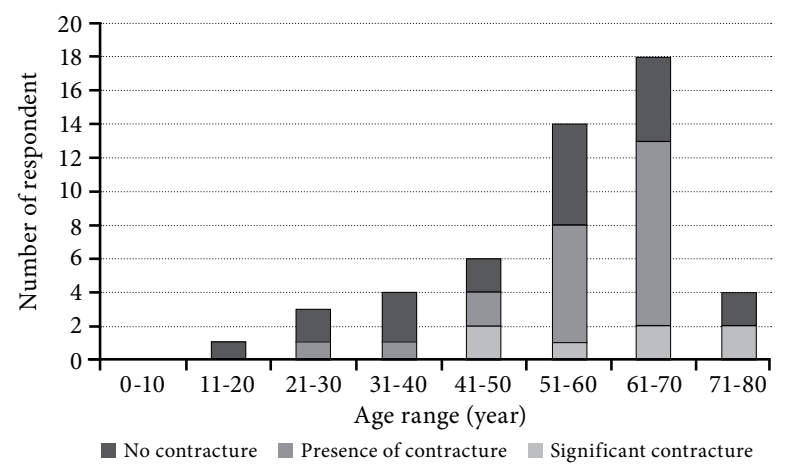

Figure 1. Chart of total participants with and without stump contracture possession based on ages.

range. The highest peak shows total participants from each group. There were three conditions:

1. Without presence of stump contracture (represented by yellow legend).

2. Presence of stump contracture (not necessarily significant).

3. Significant stump contracture (among the participants who show the presence of stump contracture).

The respondents between 18 and 78 years old and below 50 years old did not show significant differences in stump contractures occurring $(\mathrm{p}=0.052)$.

The ideal stump length for a transtibial amputee should not be less than $12.5 \mathrm{~cm} \cdot{ }^{[10,11]}$ In this study, a stump was considered to be long, if it was an ideal length and short, if vice versa. Figure 2 shows the division of respondents according to stump category along with the presence of stump contractures. There were three categories of stump contracture similar

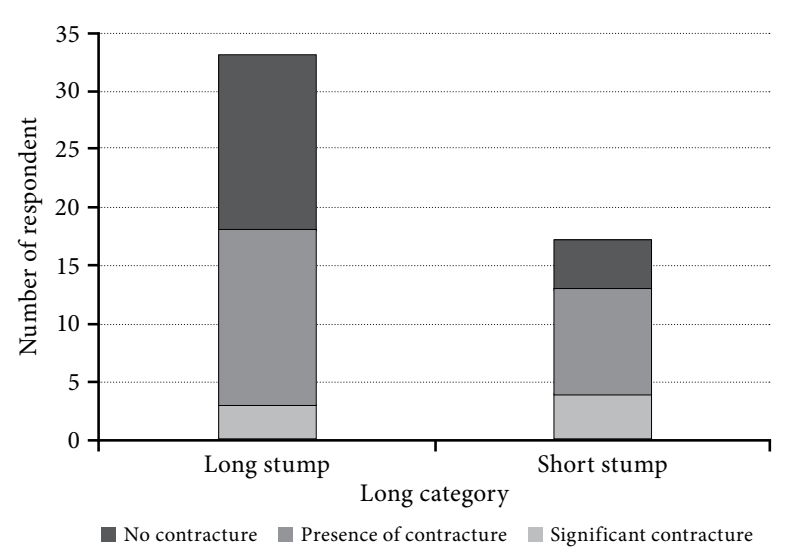

Figure 2. Stump category with the presence of contracture. to Figure 1. There were no significant differences between long and short stumps and the occurrence of stump contractures $(\mathrm{p}=0.13)$.

The participants were considered to have awareness about knee flexion contractures, if they managed to correctly define stump contractures, even if they provided their own definition of it. It was also found that respondents who were amputated at state hospitals exhibited a greater level awareness, compared to those amputated at private hospitals. However, the difference in awareness was not significant (0.125). Figure 3 shows the division of respondents according to the category of hospitals and their awareness of stump contractures.

The descriptions related with the association of two variables based on the $\mathrm{p}$ values obtained in this study are tabulated in Table 2.

The study considered a respondent to have good compliance with contracture prevention methods, if they avoided improper sitting and lying positions. This was ascertained by questions in the iii. Knee Contracture Awareness section within the questionnaire. Furthermore, at least one stump contracture prevention method should also be practiced, once per day, before a respondent was considered to have good compliance with contracture prevention methods. Figure 4 demonstrates the respondent compliance chart.

A total of 30 respondents had good compliance with contracture prevention methods. Of the 30 respondents identified, $93.3 \%$ of them practiced active exercise which was defined as, moving the stump in a full range of motion by using their own muscle power. Moreover, among these 30 respondents, $70 \%$ of them underwent physiotherapy sessions after the amputation and all

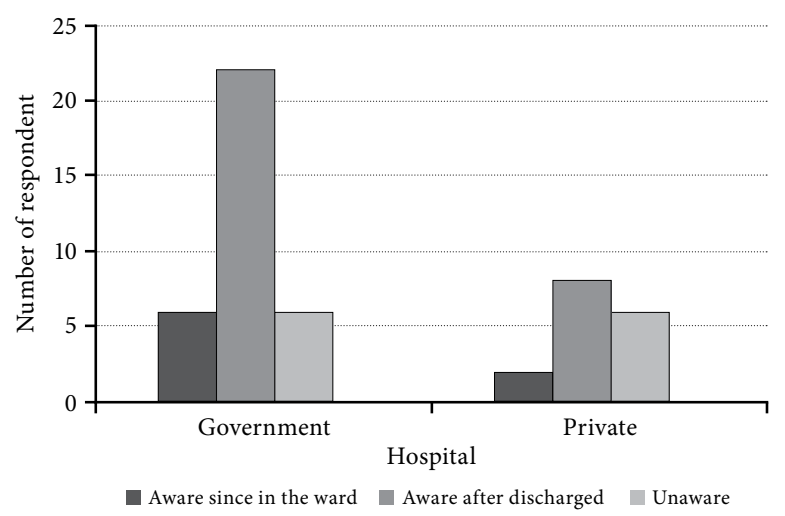

Figure 3. Distribution of participants based on the category of hospital with their awareness toward stump contracture. 
Table 2. The p-values with descriptions regarding the association between two variables

\begin{tabular}{|c|c|c|c|}
\hline \multirow[b]{2}{*}{$\mathrm{p}$-value } & \multicolumn{2}{|c|}{ Two variables } & \multirow[b]{2}{*}{ Description } \\
\hline & Variable 1 & Variable 2 & \\
\hline $\mathrm{p}=0.001$ & $\begin{array}{l}\text { Stump contracture occurrence among } \\
\text { the amputees who were amputated due } \\
\text { to diabetic complications }\end{array}$ & $\begin{array}{c}\text { Stump contracture occurrence among } \\
\text { the amputees who were amputated due } \\
\text { to the other complications/cause of } \\
\text { amputation }\end{array}$ & $\begin{array}{l}\text { The amputees who were } \\
\text { amputated due to diabetic } \\
\text { complications exhibited } \\
\text { significantly higher contracture } \\
\text { occurrence compared to the other } \\
\text { complications/cause } \\
\text { of amputation. }\end{array}$ \\
\hline $\mathrm{p}=0.052$ & $\begin{array}{l}\text { Stump contracture occurrence among } \\
\text { the amputees aged } 50 \text { years and above }\end{array}$ & $\begin{array}{l}\text { Stump contracture occurrence among } \\
\text { the amputees aged below } 50 \text { years. }\end{array}$ & $\begin{array}{l}\text { There was no significant } \\
\text { difference of the stump contracture } \\
\text { occurrence among the amputees aged } \\
50 \text { years and above and below } \\
50 \text { years. }\end{array}$ \\
\hline $\mathrm{p}=0.13$ & $\begin{array}{l}\text { Stump contracture occurrence among } \\
\text { the amputees with long stump }\end{array}$ & $\begin{array}{l}\text { Stump contracture occurrence among } \\
\text { the amputees with short stump }\end{array}$ & $\begin{array}{c}\text { There was no significant difference } \\
\text { between the amputees with short and } \\
\text { long stump in stump contracture } \\
\text { occurrence. }\end{array}$ \\
\hline $\mathrm{p}=0.125$ & $\begin{array}{l}\text { Amputees who were amputated at } \\
\text { government hospitals and aware about } \\
\text { stump contracture }\end{array}$ & $\begin{array}{c}\text { Amputees who were amputated at } \\
\text { private hospitals and aware about } \\
\text { stump contracture }\end{array}$ & $\begin{array}{l}\text { There was no significant difference in } \\
\text { contracture awareness level between } \\
\text { amputees who were amputated at } \\
\text { government and private hospitals. }\end{array}$ \\
\hline
\end{tabular}

of them marked the manual stretching box in the questionnaire, which indicated that the therapists were doing the stretching for them. Indeed, only $33.3 \%$ of good compliance respondents did active stretching i.e. muscle stretching activities, by themselves. It was found that $40 \%$ of respondents who had good compliance with contracture prevention methods were provided with stump splints. Additionally, they claimed that most of the time they wore it,

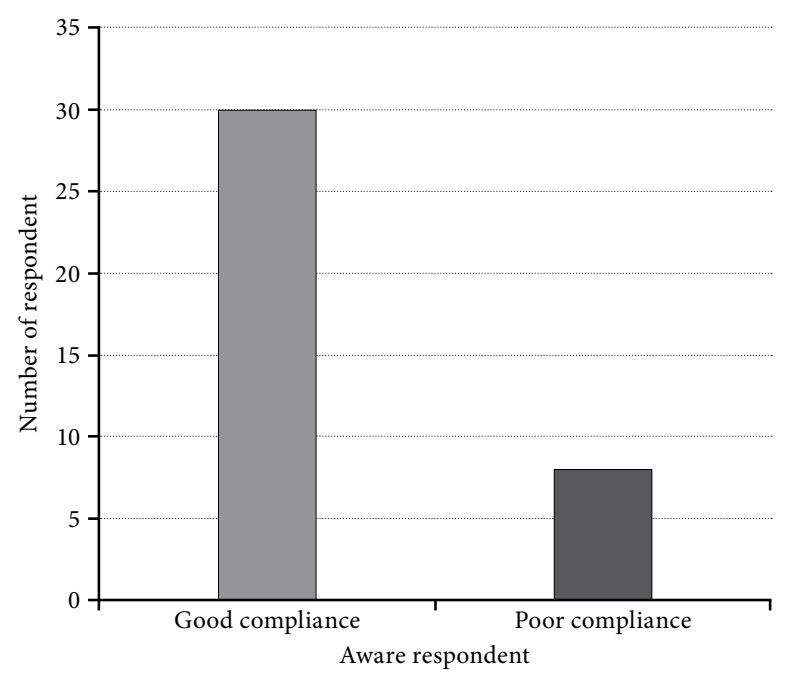

Figure 4. Compliance among the aware participants. particularly during resting. However, the duration varied for each respondent. Meanwhile, 50\% of the participants who did not have good compliance with proper sitting and lying positions still practiced some of the other contracture prevention methods. The methods included going for physiotherapy sessions and practicing both active and manual stretching. The other $30 \%$ claimed that they were doing active exercise alone. Furthermore, $16.7 \%$ of the participants who were not aware about stump flexion contractures before, were found practicing active

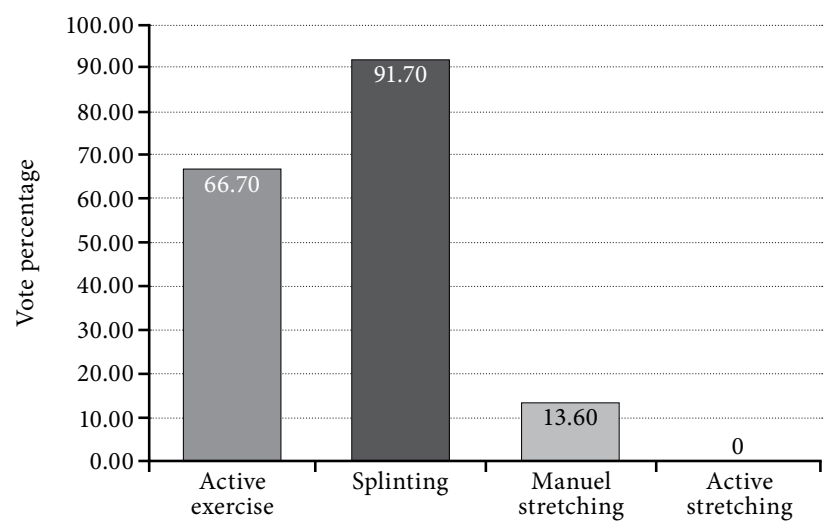

Figure 5. Votes percentage for the most comply contracture prevention method. 
exercise. Table 3 shows the contracture prevention methods practiced by the different respondents.

The most complied with/preferred stump contracture prevention method was active exercise which received 22 votes (66.7\%) from 33 respondents who were practicing it. Meanwhile, 11 votes (91.7\%) were received from respondents who were practicing stump splinting. Manual stretching only received three votes $(13.6 \%)$. None of the participants voted for active stretching. Instead, it was the only method in this study which was rated as the most uncomfortable/difficult method by eight (72.7\%) of the participants who practiced it. Therefore, based on these votes, it shows that the splinting method was the contracture prevention method that was most complied with. Figure 5 provides a clearer view regarding the votes received for the contracture prevention methods most complied with. The votes were provided by participants who practiced the methods themselves.

\section{DISCUSSION}

In the present study, the most common method of treating stump contractures was active exercise (Table 3). This could be due to the fact that exercise was free and no additional devices were required. Active exercise was, then, followed by manual stretching exercises, which was done by physiotherapists for all those who attended physiotherapy programs. It was found that manual stretching was only practiced during physiotherapy sessions. None of the respondents' families or friends assisted the patients with stretching at home. The result indicates a lack of awareness by amputees' family members or friends with flexion contracture complications. This could be due to their unwillingness to practice the stretching exercise with the patients or they had never been exposed to the method. All of the amputees who were provided with a stump splint $(\mathrm{n}=12)$ were wearing the splint at varied times and durations. Meanwhile, the low percentage of respondents who practiced active stretching was either, as there was a lack of compliance with the method or they were unaware about it. Active stretching was the only method in this study which was voted as the most difficult/uncomfortable method by $72.7 \%$ of the participants who practiced it. This finding illustrates that contracture prevention methods which required a lot of effort and were long in duration was not preferred and was most likely to be neglected by the amputees.

The low percentage of awareness of patients regarding stump contractures right after amputation in both state and private hospitals indicates that the awareness toward contractures was not obtained in the very early stages. It was found that $70 \%$ of the amputees were themselves well taught by medical rehabilitation doctors and CPO about their situation with contractures. During occupational therapy sessions, they were again reminded about awareness of contracture prevention methods by the $\mathrm{CPO}$ and the physiotherapists. ${ }^{[5,12]}$ The lack of awareness in the early stages of post-amputation could lead to flexion contracture complications with the stump, as contracture prevention methods and appropriate stump positions may not be practiced in the early stages. Furthermore, the patient's activity would normally become very limited at this stage and, thereby, leading to contractures, not only at the knee joint, but also at the hip joint. ${ }^{[12]}$ In addition, the lying position of the patient on the hospital bed either before or after surgery is also strongly related to contractures. ${ }^{[12]}$ Most of the patients were likely to raise the head part of the bed up and maintain the knees in a comfortable flexed position, which could contribute to both knee and hip contractures. ${ }^{[13]}$ The patients may maintain these improper positions even after they were discharged from the hospital, particularly if they are unaware

Table 3. Types of contracture prevention methods practiced by the subjects

\begin{tabular}{|c|c|c|c|c|c|c|}
\hline \multirow[b]{2}{*}{$\begin{array}{l}\text { Contracture prevention } \\
\text { methods }\end{array}$} & \multicolumn{3}{|c|}{ Total response } & \multicolumn{3}{|c|}{ Percentage response (\%) } \\
\hline & $\begin{array}{c}\text { Good } \\
\text { compliance } \\
(n=30)\end{array}$ & $\begin{array}{c}\text { Poor } \\
\text { compliance } \\
(n=8)\end{array}$ & $\begin{array}{c}\text { Unaware of } \\
\text { contracture } \\
(\mathrm{n}=12)\end{array}$ & $\begin{array}{l}\text { Good } \\
\text { compliance }\end{array}$ & $\begin{array}{c}\text { Poor } \\
\text { compliance }\end{array}$ & $\begin{array}{l}\text { Unaware of } \\
\text { contracture }\end{array}$ \\
\hline Stump splint & 12 & - & - & 40.0 & - & - \\
\hline Active stretching & 11 & - & - & 33.3 & - & - \\
\hline $\begin{array}{l}\text { Manual stretching during } \\
\text { physiotherapy }\end{array}$ & 21 & 1 & - & 70.0 & 12.5 & - \\
\hline Active exercise & 28 & 3 & 2 & 93.3 & 37.5 & 16.7 \\
\hline
\end{tabular}


about contractures in the early stages. Therefore, the risky timing of awareness should be overcome by implementing knowledge about contractures as soon as amputation surgery is completed.

Patients' compliance with medical care or treatment is a very important factor which may determine the objective achievement. ${ }^{[8]}$ Thus, this study examined the compliance of transtibial amputees with stump contracture prevention methods and proper stump positions. The respondents who were aware of stump contractures exhibited a high percentage of compliance (78.9\%). The result indicates the effectiveness of the rehabilitation teams in increasing awareness of contractures among amputees. It also reflects the positive attitudes and responses of amputees in Malaysia toward stump care efforts. In addition, based on the results, it can be seen that more than half of the participants treated at state hospitals (64.7\%) became aware of stump contractures after being discharged from the ward, when they were referred to the rehabilitation department. The results also prove the significant role rehabilitation specialists play in notifying and teaching patients about contracture complications. The rehabilitation specialists were also responsible for conducting flexion contracture prevention methods and increased patient awareness on proper lying and sitting positions. The results also demonstrated that the percentage of respondents who were unaware of contracture prevention methods was greater, when they were treated at private hospitals (37.5\%), compared to state hospitals (17.6\%). However, the respondents who continued to receive treatment and consultation at private hospitals by attending rehabilitation programs were completely aware of flexion contracture complications. Thisfinding suggests that the high percentage of unaware respondents was due to the discontinuation of treatment from private hospitals. The halt in treatment could be due costs or a lack of compliance with treatment.

Figure 5 shows that among 12 of the participants who obtained a stump splint from hospitals ${ }^{[11]}$ of them (91.7\%) selected this at the most preferable method to prevent stump contractures. This percentage was higher compared to the participants who selected active exercise, making it the most compliant-tolerable method in reducing/preventing flexion contractures. The result could be due to the easy resting position of the stump rather than using energy and effort to do exercise or other stretching activities. The vote for active exercise as the most preferable prevention method also exhibited a high percentage (66.7\%) among respondents who were practicing it. Despite the fact that this method required effort from the respondents, it was handy, free, and could be done anywhere, at any time. As a result, the most compliant method to prevent/reduce contractures was the one which was cost-effective, practical at any place, and required less effort. Therefore, to ensure good compliance with prevention methods from the amputees, more focus should be placed on the stump splint for the stretching method. Moreover, for the exercise method, more priority should be placed on active exercise.

Based on these findings, the significant occurrence of stump contractures among diabetic patients can be proved theoretically. This is because musculoskeletal disorders are normally associated with diabetic complications. The complication would lead to a reduction in functional abilities, physical inactivity, and a lower quality of life. ${ }^{[9]}$ In similar cases, it was common to find that elderly patients were less active in musculoskeletal activities, compared to younger patients. This population also had more problems with rehabilitation in terms of compliance and body tolerance. ${ }^{[14]}$ Therefore, although the difference was not significant, it was expected to see a higher numbers of elderly amputees developing contractures compared to younger amputees. In addition, based on the literature, transtibial amputees with short residual limbs have a higher risk of developing contractures. ${ }^{[5,13-15]}$ Thus, amputees with a greater risk of developing contractures, should be given more attention and effort in order to prevent/reduce stump contractures.

The data gathered from this questionnaire were sufficient for this study to achieve its objectives that was to assess the level of awareness of transtibial amputee patients on stump contractures and their compliance with efforts implemented to prevent the condition. Nonetheless, the limited number of respondents resulted in some of the findings in certain aspects becoming invalid and was unable to be further discussed. In the future, certain aspects that require an adequate number of participants would be determined and classified accordingly, rather than a random search for the respondents.

In conclusion, hospitals play a major role in implementing the knowledge of post-amputation care for amputees. Therefore, rehabilitation programs should be highly correlated with post-amputation treatment. More focus should be placed on contracture prevention methods which are most preferred and complied to optimize the outcomes. Furthermore, the 
amputees who face a greater risk of developing stump contractures should be given more attention and rapid treatment/therapy.

\section{Declaration of conflicting interests}

The authors declared no conflicts of interest with respect to the authorship and/or publication of this article.

\section{Funding}

This study was supported by the Malaysia UM/PPP/ PG100-2016A.

\section{REFERENCES}

1. Katalinic OM, Harvey LA, Herbert RD. Effectiveness of stretch for the treatment and prevention of contractures in people with neurological conditions: a systematic review. Phys Ther 2011;91:11-24.

2. Mollinger LA, Steffen TM. Knee flexion contractures in institutionalized elderly: prevalence, severity, stability, and related variables. Phys Ther 1993;73:437-44.

3. Finger E, Willis FB. Dynamic splinting for knee flexion contracture following total knee arthroplasty: a case report. Cases J 2008;1:421.

4. Wright JG, Menelaus MB, Broughton NS, Shurtleff D. Natural history of knee contractures in myelomeningocele. J Pediatr Orthop 1991;11:725-30.

5. LaRaia N. Ask The Physical Therapist. In Motion 2010;20:334.

6. Munin MC, Espejo-De Guzman MC, Boninger ML, Fitzgerald SG, Penrod LE, Singh J. Predictive factors for successful early prosthetic ambulation among lower-limb amputees. J Rehabil Res Dev 2001;38:379-84.

7. Smith DG, McFarland LV, Sangeorzan BJ, Reiber GE, Czerniecki JM. Postoperative dressing and management strategies for transtibial amputations: a critical review. J Rehabil Res Dev 2003;40:213-24.

8. Coletta EM. Care of the elderly patient with lower extremity amputation. J Am Board Fam Pract 2000;13:23-34.

9. Shaw KM, Cummings MH. Diabetes: Chronic Complications. 2nd ed. West Sussex: John Wiley \& Sons; 2005.

10. Subbarao KV, Bajoria S. The effect of stump length on the rehabilitation outcome in unilateral below-knee amputees for vascular disease. Clin Rehabil 1995;9:327-30.

11. Isakov E, Burger H, Gregoric M, Marincek C. Stump length as related to atrophy and strength of the thigh muscles in trans-tibial amputees. Prosthet Orthot Int 1996;20:96-100.

12. Nehler MR, Coll JR, Hiatt WR, Regensteiner JG, Schnickel GT, Klenke WA, et al. Functional outcome in a contemporary series of major lower extremity amputations. J Vasc Surg 2003;38:7-14.

13. O’Sullivan SB, Schmitz TJ, Fulk G. Physical Rehabilitation. 6th ed. Pennsylvania: F.A. Davis; 2013, p. 1389.

14. MurnaghanJJand BowkerJH. Musculoskeletal complications. In: Smith DG, Michael JW, Bowker JH, editors. Atlas of amputations and limb deficiencies: surgical, prosthetic and rehabilitation principles. 3rd ed. Rosemont, IL: American Academy of Orthopaedic Surgeons; 2004. p. 683-99.

15. Lenka $P$ and Tiberwala DN. Effect of stump length on postural steadiness during quiet stance in unilateral transtibial amputee. Al Ameen J Med Sci 2010;3:50-7. 


\section{Appendix I}

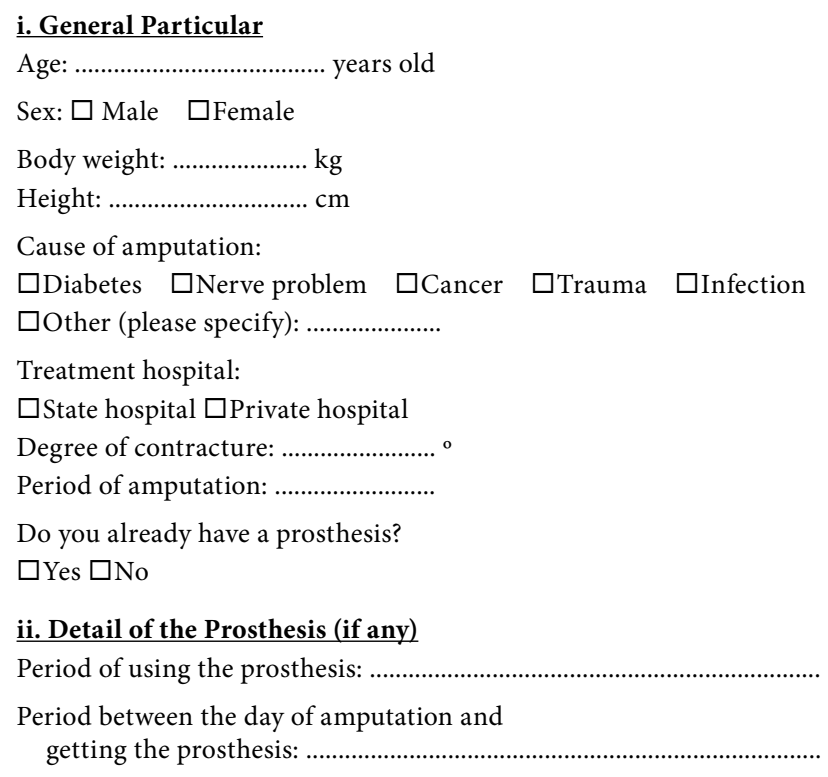

Are you doing any exercise involving the stump when you are not wearing the prosthesis?

$\square$ Yes (please specify): $\square$ No

iii. Knee Contracture Awareness

Do you know what a knee contracture is / how is the condition?

$\square$ Yes $\square$ No

If $\square$ Yes, please define:

If $\square$ Yes, when you started to know about the knee contracture?

$\square$ Since in the ward, after being amputated

$\square$ After being referred to physiotherapy/occupational therapy

$\square$ After being referred to rehabilitation doctor

$\square$ After seeing the prosthetist

$\square$ Other (please specify):

Does anybody teach you about knee contracture prevention in terms of methods or ideal body position?

$\square$ Doctor $\square$ Nurse $\square$ Physiotherapy $\square$ Occupational therapy

$\square$ Other (please specify): $\square$ Nobody

Did you experience worse knee contractures before?

$\square$ Yes

How bad was it?

Very mild $\rightarrow$\begin{tabular}{|l|l|l|l|l|l|l|l|l|l||l|}
\hline 1 & 2 & 3 & 4 & 5 & 6 & 7 & 8 & 9 & 10 & — Very bad \\
\hline
\end{tabular}

$\square$ No

$\square$ Not sure
What is/are the most preferred lying position(s) on the hospital bed/bed at home? (tick whichever relevant)

$\square$ Head up $\square$ Prone position $\square$ Extend the residual knee

$\square$ Put something under the residual knee to flex it $\square$ Sleep on the side $\square$ Leave the stump hanging at the edge of the bed $\square$ Sitting position

$\square$ Other (please specify):

What is the most preferred position of stump during sitting/sleeping? $\square$ Flexion $\square$ Extension

What mechanism(s) do you use to prevent/reduce the knee contracture? (tick whichever relevant)

$\square$ Active exercise (please specify how frequent):

$\square$ Active stretching (please specify how frequent):

$\square$ Manual stretching (please specify how frequent):

$\square$ Splinting (please specify the duration):

$\square$ Nothing

Which one you comply with/prefer the most?

$\square$ Active exercise $\square$ Active stretching $\square$ Manual stretching

$\square$ Splinting $\square$ Not sure

Which one is most difficult/uncomfortable?

$\square$ Active exercise $\square$ Active stretching $\square$ Manual stretching

$\square$ Splinting $\square$ Not sure

Can you feel the improvement?

$\square$ Yes

How good it was?

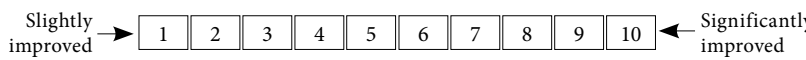

\section{$\square$ No}

$\square$ Not sure

Do you have any physiotherapy sessions after surgery?

$\square$ Yes (please specify how frequent): $\square$ No

When you already had the prosthesis, do you keep practicing the knee contracture prevention mechanism?

$\square$ Yes $\square$ No

Since using the prosthesis, do you feel any improvements in the contracture? (for those who discontinue the knee contracture prevention mechanism after getting the prosthesis)

$\square$ Yes $\square$ No $\square$ Not sure 